\title{
METODOLOGIAS ATIVAS DE ENSINO APRENDIZAGEM: CONSIDERAÇÕES SOBRE PROBLEMAS, PROJETOS E INSTRUÇÃ̃ ${ }^{1}$
}

\author{
Active Teaching Methodologies learning: Considerations on Problems
}

Zilda Gonçalves de Carvalho Mendonça - Universidade de Rio Verde/Brasil

\begin{abstract}
RESUMO: As metodologias ativas de ensino-aprendizagem consideram os alunos como agentes ativos no processo educativo. Para as metodologias ativas de ensino, os recursos tecnológicos são imprescindíveis na realização das atividades e estudo. Objetivou-se investigar os processos de ensino-aprendizagem, tradicionais e ativos, apontando as principais diferenças entre os mesmos apresentando considerações sobre as metodologias de ensino-aprendizagem baseadas em problemas, em projetos e por instrução. Para esse estudo, privilegiou-se a revisão de literatura, as quais apresentavam dados de estudos de casos das aplicações dos diferentes métodos. Constatou-se que os métodos possuem propriedades distintas em suas aplicações e que cada um possui peculiaridades

Palavras-chave: Instrução. Metodologias Ativas. Problemas. Projetos.
\end{abstract}

ABSTRACT: Active teaching-learning methodologies consider students as active agents in the educational process. For the active methodologies of teaching, the technological resources are essential for the accomplishment of the activities and study. The purpose of this study was to investigate the teaching and learning processes, traditional and active, pointing out the main differences between them, presenting considerations on teaching-learning methodologies based on problems, in projects and by instruction. For this study, the literature review was privileged, which presented data from case studies of the applications of the different methods. It was found that the methods have different properties in their applications and that each has peculiarities.

Keywords: Instruction. Active methodologies. Problem.; Projects.

\section{INTRODUÇÃO}

Há algum tempo, as práticas tradicionais de ensino vêm passando por revisões, uma vez que não conseguem atender as exigências contextuais da contemporaneidade. Diante disso, os problemas relacionados ao cotidiano do ensino-aprendizagem parecem se agigantar de forma acelerada. Nesse cenário, as soluções propostas para formar e educar as gerações passadas não conseguem atender aos interesses e habilidades

\footnotetext{
${ }^{1}$ Estudo realizado com financiamento da Pró-Reitoria de Pesquisa da UNIRV. Parte deste texto foi objeto de apresentação oral no Encontro PIBId/Curitiba/2016. O resultado da discussão apresentada resultou em resumo expandido, publicado na revista eletrônica PRODOCÊNCIA/UNIRV.
}

Educação, Psicologia e Interfaces, Volume 2, Número 3, p. 57-70, Setembro/Dezembro, 2018. 
necessárias à geração Z, a qual vive num contexto de muitíssimas e variadas informações em constante atualização.

Instituições escolares e educacionais têm buscado adotar/inserir em seus projetos de cursos, as metodologias ativas de ensino e de aprendizagem. O objetivo é motivar, despertar e desafiar os estudantes a estudar e aprender de forma significativa, visto que no mundo atual, aprender não se reduz à memorização, mas associa-se à capacidade de compreender, raciocinar, analisar.

Isto posto, salienta-se que este estudo trata sobre as metodologias ativas e as tradicionais destacando o papel do docente no processo de ensino-aprendizagem. A discussão e reflexão sobre o ensino-aprendizagem evidenciam relevância do papel do docente do momento contemporâneo, possibilitando o pensar sobre as metodologias utilizadas em sala de aula e a eficácia/eficiência das práticas do docente nesse processo.

Diante do exposto, considerou-se questões que decorrem da seguinte situação: os professores passam, com frequência, por formação continuada, ocasião em que são sugeridas metodologias e dinâmicas para diversificar as práticas pedagógicas de ensinoaprendizagem em sala de aula. Para este estudo objetivou-se investigar os processos de ensino-aprendizagem, tradicional e ativos, apontando as principais diferenças entre os mesmos, bem como apresentar considerações a respeito das metodologias de ensinoaprendizagem baseadas em problemas, em projetos e por instrução.

O estudo para aprofundamento teórico foi realizado por meio de pesquisa bibliográfica, com levantamento em livros, artigos, teses e sites de internet. A pesquisa bibliográfica teve o propósito de compreender as bases teóricas do estudo, envolvendo metodologias ativas no processo de ensino-aprendizagem, buscando identificar os pontos de integração do ensino tradicional às novas metodologias. Buscou-se selecionar exemplos ou estudos de casos que pudessem servir de referência para que fossem abordadas as metodologias ativas de ensino-aprendizagem escolhidas para o estudo.

\subsection{SOBRE A TAREFA DE ENSINAR}

O século XXI nasceu exigindo múltiplas transformações em todos cos campos do conhecimento da vida ou existência planetária. No que diz respeito à educação, muito há o que se estudar e a compreender, desde o contexto onde ocorre, seus sujeitos, seus objetivos, seus desafios. 
Metodologias Ativas de Ensino Aprendizagem: considerações sobre Problemas, Projetos e Instrução

Dentre tantos estudos que vêm sendo realizados, há aqueles que propõem a migração do ensino através de disciplinas para uma proposta interdisciplinar que privilegie metodologias ativas, professores altamente preparados sob rigorosa fundamentação orientada sob o paradigma da produção do conhecimento enraizado na realidade social e que consigam tratar os alunos como sujeitos do processo de aprendizagem, completamente antenados com as necessidades de seu tempo.

De modo geral, relacionando valores e habilidades, Goldberg (2012) assinala "as 7 coisas que estão faltando" na formação de alunos. Segundo ele, os alunos, já no final dos cursos, estão apresentando dificuldades para: fazer boas perguntas; nomear objetos tecnológicos; modelar processos e sistemas; decompor problemas complexos em problemas menores; coletar dados para análise; visualizar soluções e gerar novas ideias; e comunicar soluções de forma oral e por escrito.

Essa constatação alerta aos estudiosos, professores e demais envolvidos no processo ensino-aprendizagem sobre a condição do aprendiz na atualidade. Este não assimila simplesmente o que lhe é apresentado, da mesma forma que não "absorve" ou apropria do que lhe é "repassado".

[...] os docentes necessitam refletir permanentemente sobre suas ações, objetivos e resultados de sua prática educativa, sem perder o foco no aluno, para que possam oferecer diferentes cenários de aprendizagem, já que ensinar significa provocar conflitos que, apresar de assustadores, são necessários para a experiência do saber, de modo a estimular as potencialidades e as múltiplas inteligências de nossos estudantes. (GOLDBERG, 2012, p. 22)

Assim, nota-se que aprendizagem é um processo complexo. Diante do novo conhecimento apresentado, o sujeito imediatamente o relaciona com (pré)conceitos, crenças ou interesses, por vezes, distorcendo seu sentido ou significado, aproximando-o a uma visão de mundo muito particular. Diante disso,

A tarefa de ensinar um saber elaborado passa por um processo prévio em que os alunos aprendem a pensar melhor, a problematizar, a valorizar o conhecimento e a se comprometer com a busca investigativa. Parte-se dos fenômenos familiares a respeito dos quais a classe tem o que dizer. No diálogo, as ideias vão tomando corpo, tornando-se mais precisas. O conflito de pontos de vista aguça o espírito crítico, estimula a revisão das opiniões, contribui para relativizar posições. O momento da revisão do debate permite ao grupo refazer os caminhos percorridos, retraçando sua trajetória intelectual, tornando os

Educação, Psicologia e Interfaces, Volume 2, Número 3, p. 57-70, Setembro/Dezembro, 2018.

ISSN: 2594-5343. DOI: https://doi.org/10.37444/issn-2594-5343.v2i3.155 


\section{Zilda Gonçalves de Carvalho Mendonça}

alunos conscientes dos processos subjacentes à discussão dos conteúdos (PIMENTA, 2002, p. 129).

A aprendizagem não é um caminho de mão dupla no qual o professor oferece o conteúdo ou conhecimento e o estudante o recebe e se apropria dele imediatamente. A aprendizagem resulta de um processo social que contempla diálogo, partilha de ideias com quem está próximo, confrontos e negociações (PIMENTA, 2002).

O termo ensino é utilizado com muita frequência, por, praticamente todas as pessoas. Contudo, quando se pede para alguém conceituar ou defini-lo, a maioria relaciona ensino ao ato pedagógico que ocorre na relação professor-aluno. Em geral, é compreendido como a transmissão de matérias ou de conteúdos aos alunos, "fixação" com exercícios repetitivos, memorizações de conceitos e fórmulas. Num momento determinado pelo professor - dia da prova - o aluno "devolve", "dá" ao professor a reprodução do que está no livro didático, apostilas ou outro material.

Ao longo dos tempos, esse conceito, embora muito utilizado, foi sofrendo alterações em seu significado, consideradas as complexidades do exercício ensinoaprendizagem dentro e fora da sala de aula. Nesse sentido, torna-se importante tratar sobre metodologias ativas enquanto recursos relevantes no processo de ensino e de aprendizagem.

\section{MATERIAL E MÉTODO}

Objetivou-se investigar os processos de ensino-aprendizagem, tradicionais e ativos, apontando as principais diferenças entre os mesmos apresentando considerações sobre as metodologias de ensino-aprendizagem baseadas em problemas, em projetos e por instrução. Para esse estudo, privilegiou-se a revisão de literatura, as quais apresentavam dados de estudos de casos das aplicações dos diferentes métodos.

\section{RESULTADOS E DISCUSSÃO}

Metodologia de ensino para muitos não passa de ação engenhosa, criativa, para se fazer uma aula diferente. Para outros, as metodologias constituem em truques "mágicos" para distrair os estudantes e dar leveza ao ambiente da sala de aula. Há, ainda, aqueles que a concebem como perda de tempo, já que não se percebem como partícipes de algum contexto não conseguem compreender o processo de ensino e de aprendizagem como algo 
Metodologias Ativas de Ensino Aprendizagem: considerações sobre Problemas, Projetos e Instrução

histórico-filosófico, cultural, antropológico, científico. Outros tantos, contudo, pretendem que as coisas e ações sejam compreendidas como estanques, soltas, imediatas, utilitárias e descartáveis.

\subsection{MÉTODOS ATIVOS/METODOLOGIAS ATIVAS}

Importante considerar que todo ato humano é intencional. $\mathrm{O}$ ato de ensinar e aprender não fogem à regra. Buscando, inicialmente, maior compreensão sobre o assunto, o Dicionário Brasileiro de Educação esclarece:

Métodos Ativos: Todos os métodos baseados na atividade constante do educando. Métodos ativos individualizados: Métodos ativos que consideram as diferenças individuais. O ensino deve ser ajustado à realidade, às possibilidades e à capacidade de cada um. Ex. Método Montessori, o Plano Dalton, o Plano Winnetka. Métodos ativos mistos: Os que procuram atender tanto a objetivos individualizadores como a objetivos socializadores. Ex. Método da Unidade de Morrison. Métodos ativos socializados. Métodos ativos cujo maior objetivo é a socialização do educando, a partir de uma ação didática. Ex. Métodos dos Centros de Interesse ou de Círculos Concêntricos de Decroly. (DUARTE, 1986, p. 120)

Ressalta-se que as tais metodologias ativas não constituem assunto tão novo, não sugiram neste momento, “[...] no decorrer da época moderna, que se expressam os primeiros indícios da metodologia ativa" (ARAÚJO, 2015, p. 6). Sublinha que, entre a última década do século XIX e as três primeiras décadas do século XX, a escola e a educação sofreram profundas e radicais transformações. Foram abertas às massas, tornaram-se ideológicas e afirmaram-se como centrais na sociedade (CAMBI, 1999).

Essa renovação foi maior no âmbito da tradição ativista, quando a escola se impôs como instituição-chave da sociedade democrática e se nutriu de um forte ideal libertário, dando vida a experimentações escolares e didáticas destinadas no primado do "fazer" quanto a teorizações pedagógicas destinadas a fundar/interpretar essas práticas inovativas partindo de filosofias ou de abordagens científicas novas em relação ao passado. (CAMBI, 1999, p. 513)

Segundo Araújo (2015), a proposta para as metodologias ativas dá relevância à atividade, há vista que esta é considerada promotora da experiência que resulta em aprendizagem. A experiência que apresenta diferentes acepções no período moderno, oferecerá os primeiros fundamentos para a metodologia ativa. Nessa direção, alguns estudiosos modernos contribuíram, cada qual com suas defesas: Montaigne (1533-1592),

Educação, Psicologia e Interfaces, Volume 2, Número 3, p. 57-70, Setembro/Dezembro, 2018. 
Comênio (1592 - 1670), John Locke (1632-1704), Rousseau (1712-1778), Herbart (17761841).

De modo geral, quando se pergunta a um professor o que ele compreende por aprendizagem ativa, a resposta aponta para a participação do aluno que, ativamente se envolve no processo de produção do conhecimento, exercitando seu raciocínio, seu pensamento, sua observação, entendimento, reflexão, entendimentos, relações, confrontos, análise, síntese, avaliação e apresentação do que aprendeu.

Nesse contexto, as metodologias ativas de ensino e aprendizagem aparecem como alternativas capazes de atender às demandas e desafios da educação atual. Embora seja considerada como de potencial eficácia, a aplicação dessas metodologias exige compreensão aprofundada de seus fundamentos e de sua capacidade de apresentar resultados promissores nos processos de ensino e aprendizagem.

[...] aprendizagem ativa ocorre quando o aluno interage com o assunto em estudo - ouvindo, falando, perguntando, discutindo, fazendo e ensinado - sendo estimulado a construir o conhecimento ao invés de recebe-lo de forma passiva do professor. Em ambiente de aprendizagem ativa, o professor atua como orientador, supervisor, facilitador do processo de aprendizagem, e não apenas como fonte única de informação e conhecimento. (BARBOSA; MOURA, 2013, p. 55)

Mas introduzir essa proposta nas práticas pedagógicas, em qualquer nível de ensino, implica na disposição de enfrentar muitos e diferentes desafios. Dentre muitos, salienta-se a cultura ao tradicional e consolidado método expositivo, pelo o qual professor, alunos e sociedade têm "a certeza de que a aula foi dada". Parece que o entendimento de se lançar em busca de formas diferentes de ensinar e aprender soam como traição ao método que permeou e fundamentou o contexto escolar por tanto tempo.

Vale considerar e compreender as dificuldades e resistências que são encontradas nos momentos de aplicação de metodologias ativas em situações práticas de ensino e aprendizagem. Assim, tornam-se salientes as resistências à implementação de novos métodos de ensino, especialmente os ativos em instituições e ambientes educacionais.

Há resistência da cultura escolar e do próprio aluno ao pensar. É preciso vencer a inércia e a passividade. Há descrença nos podres do diálogo e da própria razão. Há dificuldades iniciais dos alunos: sentem-se confusos, não sabem dialogar, nem trabalhar cooperativamente. Por outro lado, há tensão e esforço na criação intelectual. As atividades requerem mais tempo, obrigando o professor a fazer cortes na extensão 
Metodologias Ativas de Ensino Aprendizagem: considerações sobre Problemas, Projetos e Instrução

do programa. [...]Há também resistências no professor: nossas praticas frequentemente contradizem nosso discurso inovador. Desejamos um aluno crítico, mas não valorizamos respostas divergentes. Preocupamonos com a compreensão, mas nossas avaliações cobram sobretudo a reprodução da matéria. Reconhecemos a importância das práticas sociais no desenvolvimento intelectual, mas mantemos nossos alunos trabalhando e produzindo individualmente. Acabamos correndo com o programa, formalizando precocemente, dando respostas ao invés de dar espaço para a classe pensar (PIMENTA, 2002, p. 131-2).

De modo geral, há um discurso sobre metodologias ativas tomando corpo e sendo disseminado. Entretanto, quando se questionam os professores, a sociedade, a universidade sobre tal tema, o que se constata é que "conhecem de vista" o tema. Notase que não há preocupação em estudar, fundamentar sobre o assunto. Na prática, grande parte das pessoas, dos profissionais da educação, dos estudantes ou não, gostaria que o processo de aprendizagem fosse "meio mágico", e não exigisse qualquer compromisso de quem quer que fosse. Assim, não teria que alterar legislação, cultura, história, contexto e "não precisaria estudar".

Para tal, pretende-se uma metodologia ativa que possa ser apresentada como receita de bolo, orientando o passo a passo para acontecer e tenha o resultado garantido, independente se são professores ou alunos, se é ensino ou aprendizagem. Até porque há quem defenda que não deve haver esforço ou sofrimento por parte dos envolvidos.

\subsection{APRENDIZAGEM BASEADA EM PROBLEMAS E APRENDIZAGEM BASEADA EM PROJETOS}

A ideia de trabalhar com problemas para ensinar e aprender não é nova. Há registros históricos de indícios sobre a prática do filósofo Confúcio (500 a.C) afirmando que o mesmo ajudava os seguidores na resposta a algum problema ou questão depois que apresentassem esforço próprio na busca por solução (BARBOSA; MOURA, 2013).

Desde essa época até à atualidade, quando se busca por uma proposta pedagógica diferente da tradicional, dentre outras, destacam-se as metodologias ativas de ensino e de aprendizagem, muitas vezes, denominadas "Problematização" e Aprendizagem Baseada em Problemas". Essas, embora sejam semelhantes, são distintas. Contudo, ambas estão fundamentadas na pedagogia crítica e trabalham intencionalmente com problemas nos processos de ensino e de aprendizagem, valorizando o aprender a aprender (MARIN et al. 2010).

Educação, Psicologia e Interfaces, Volume 2, Número 3, p. 57-70, Setembro/Dezembro, 2018. 
No Brasil, a metodologia que privilegia a Problematização

se fundamenta nos princípios de Paulo Freire, tendo como referência os trabalhos de Diaz Bordenave e Pereira, pautados no arco de Maguerez, que propõe um esquema de problematização da realidade em cinco etapas: observação da realidade; identificação dos pontos-chave; teorização; hipóteses de solução; aplicação à realidade. (MARIN et al, 2010, p. 14)

Segundo Araújo (2011), a Aprendizagem Baseada em Problemas surgiu nos anos 1960, no Canadá, sendo aplicada, inicialmente, no curso de Medicina. A partir de então, a ABProb tem sido aplicada em outras áreas do conhecimento e caracteriza-se pelo

\begin{abstract}
uso contextualizado de uma situação problema para o aprendizado autodirigido. Enquanto nos métodos convencionais o objetivo é a transmissão do conhecimento centrada no professor, em conteúdos disciplinares, na ABProb, o aprendizado passa a ser centrado no aluno, que deixa de ser um receptor passivo da informação para ser agente ativo por seu aprendizado. Neste contexto, o professor atua como orientador ou facilitador nos grupos de trabalho ou estudo nos quais a interação entre professor-aluno é muito mais intensa do que em aulas puramente expositivas (BARBOSA; MOURA, 2013, p. 58).
\end{abstract}

No Brasil, a ABProb (Aprendizagem Baseada em Problemas) teve a aplicação iniciada como metodologia educacional em cursos da área da saúde, graças à insistência e dedicação da doutora Neusi Berbel, pedagoga, doutora em educação que atua na formação docente do Departamento de Educação da Universidade Estadual de Londrina (UEL), no Paraná. Essa professora e seus colaboradores têm desenvolvido pesquisas e fundamentação sobre tal procedimento. (DECKER e BOUHUIJS, 2016) O interesse por essa metodologia tem crescido e em várias instituições muitos cursos de graduação têm incluído a mesma em seus currículos.

Para que a Aprendizagem Baseada em Problemas ocorra faz se indispensável que ocorra o Ensino Baseado em Problemas. Este

[...] trabalha questões relevantes, atuais, para as quais a sociedade, as empresas ou a vida real ainda não encontraram solução. Ao analisar mais profundamente essas questões, os alunos aprendem e utilizam as disciplinas e teorias consideradas necessárias à resolução de determinado problema, isto é, os problemas definem as disciplinas e vice-versa (ENEMARK; KJAERSDAM, 2016, p. 24).

Educação, Psicologia e Interfaces, Volume 2, Número 3, p. 57-70, Setembro/Dezembro, 2018. 
Metodologias Ativas de Ensino Aprendizagem: considerações sobre Problemas, Projetos e Instrução

A problematização possibilita ao aluno o contato com as informações e oportuniza a produção de conhecimento priorizando a solução de uma situação problema, o que impulsiona o seu próprio conhecimento. Aprender com a solução de problemas próprios de sua realidade ou de sua área propicia o envolvimento ativo dos alunos no próprio processo de formação.

As diferentes discussões apontam que na Aprendizagem Baseada em Problemas devem ser seguidas algumas etapas pelos alunos: 1. entendimento inicial do problema proposto; 2. discussão de ideias (listar soluções iniciais baseadas no que já se sabe); 3 . reflexão (decompor o problema e identificar partes); 4. levantamento de questões (para orientar a investigação); 5. definição de objetivos (o que se espera aprender com esse trabalho); 6. estudo (individual e em grupo); 7. síntese e avaliação (estabelecer os resultados obtidos); 8. apresentação (mostra de processos e resultados e conclusões).

A Aprendizagem Baseada em Projetos pode ocorrer concomitante com a Aprendizagem Baseada em Problemas. Nesta direção, no trabalho com projetos

[...] os estudantes deveriam adquirir os conhecimentos básicos necessários por meio da bibliografia e cursos correspondentes e, simultaneamente, desenvolver a capacidade de formular, analisar e solucionar questões relevantes. [...] "Organizado em projetos" significa que o currículo é dado no trabalho com projetos, com o complemento de cursos teóricos e a prática como atividade complementar. A ideia de organização em projetos afasta a perspectiva da descrição e analise dos conhecimentos e situa na síntese e na avaliação (ENEMARK; KJAERSDAM, 2016, pp. 24-5).

Outro elemento é que "O objetivo do trabalho com projetos é "aprender a fazer" ou "aprender na ação" (ENEMARK; KJAERSDAM, 2016, p. 26). Segundo Barbosa e Moura (2013), a proposta para a aprendizagem baseada em projetos, também chamados de projetos de trabalho ou metodologia de projetos, podem ser classificadas em três tipos: (a) Projetos de Aprendizagem do tipo Explicativo (ou didático): objetiva mostrar e explicar o funcionamento de objetos tecnológicos, analisando as partes fundamentais de um dispositivo, equipamento ou sistema. $\mathrm{O}$ aluno identifica e se familiariza com conceitos e conhecimentos científicos ali aplicados. (b) Projetos de aprendizagem do tipo construtivo: objetiva a construção de algo que pode ser um equipamento, dispositivo ou um sistema para cumprir uma finalidade determinada. (c) Projetos de aprendizagem do tipo investigativo: objetiva vivenciar o processo da ciência. Requer um prazo mais longo

Educação, Psicologia e Interfaces, Volume 2, Número 3, p. 57-70, Setembro/Dezembro, 2018. 
de execução e domínio dos processos de medidas, análise de dados e uma orientação cuidadosa do professor, principalmente na fase de formulação da questão de pesquisa científica.

Recomendações para o método de Aprendizagem Baseado em Projetos: 1. grupos de trabalho com número reduzido de alunos (4 a 6 alunos); 2. definição de prazos para concretização do projeto ( 2 a 4 meses); 3. definição de temas via negociação entre alunos e professor; 4. finalidade útil para os projetos para que os alunos percebam um sentido real dos mesmos; 5. uso de múltiplos recursos, incluindo aqueles providenciados pelos próprios alunos dentro ou fora do ambiente escolar; 6. socialização dos resultados dos projetos em diversos níveis, como a sala de aula, a escola e a comunidade.

\subsection{APRENDIZAGEM BASEADA EM INSTRUÇÃO (PEER INSTRUCTION)}

É consenso que a sala de aula tradicional não oferece oportunidades para que o estudante aprenda a pensar. Contudo, nela, há um esforço soberbo para se chegar ao resultado. E tudo de diferente que for proposto em sala, só será aceito se houver o "estímulo" da nota. Trabalhos e estudos em grupos são diluídos em atividades individuais, uma vez que os estudantes fragmentam o tema - na ilusão de diminuírem os trabalhos e estudos e "eliminarem" aquela etapa o mais rápido possível, - não prevalecendo as discussões e investigações coletivas.

Um problema do ensino tradicional é apresentação do conteúdo. Com frequência, é tirado diretamente dos livros ou das notas de aulas do professor, dando aos estudantes pouco incentivo para assistir às aulas. O problema é apresentação tradicional do conteúdo, que consiste quase sempre em um monólogo diante de uma plateia passiva. Somente professores excepcionais são capazes de manter os estudantes atentos durante toda uma aula expositiva. Mais difícil ainda é dar oportunidades adequadas para que os estudantes pensem de forma crítica, usando argumentos que estão sendo desenvolvidos. Consequentemente, as aulas expositivas simplesmente reforçam os sentimentos dos estudantes de que o passo mais importante para dominar o conteúdo está na solução de problemas (MAZUR, 2015, p. 11).

Aprendizagem Baseada em Instrução é o método que se baseia no estudo preliminar de temas e assuntos pelos alunos. O professor orienta o tema e suas literaturas básicas. Os alunos têm o trabalho de pesquisar e estudar. Antes da aula expositiva pelo professor, os alunos fazem contato com o professor, por meio de chat, para averiguar capacidade de responder questões relacionadas ao tema. No momento da aula expositiva,

Educação, Psicologia e Interfaces, Volume 2, Número 3, p. 57-70, Setembro/Dezembro, 2018.

ISSN: 2594-5343. DOI: https://doi.org/10.37444/issn-2594-5343.v2i3.155 
Metodologias Ativas de Ensino Aprendizagem: considerações sobre Problemas, Projetos e Instrução

os alunos fazem inicialmente uma avaliação, quando o professor consegue detectar quem realmente estudou e o que conseguiram aprender. Somente os alunos que estudaram, podem participar da aula expositiva, pois, assim, terão condições para argumentarem e acrescentarem ao conteúdo já estudado.

Os objetivos básicos da Peer Instruction são: explorar a interação entre estudantes durante as aulas expositivas e focar a atenção dos estudantes nos conceitos que servem de fundamento. Em vez de dar aula com o nível de detalhamento apresentado no livro ou nas notas de aula, as aulas consistem em uma série de apresentações curtas sobre os pontoschave, cada uma seguida de um teste conceitual pequenas questões conceituais abrangendo o assunto que está sendo discutido. A princípio é dado um tempo para os estudantes formularem suas respostas e, em seguida, eles devem discuti-las entre si. Esse processo (a) força os estudantes a pensar com base nos argumentos que estão sendo desenvolvidos e (b) dá-lhes (o professor incluído) um modo de avaliar sua compreensão do conceito (MAZUR, 2015, p. 10).

O método de Ensino por Instrução exige uma preparação prévia dos alunos e do professor, pode-se enumerar algumas etapas para o método de aprendizagem por instrução: 1. Informar o aluno do processo o qual ele está inserido; 2. Estudo prévio; 3. Avaliação por chat ou programas específicos; teste conceitual; 4. Breve exposição; 5. Discussão em grupo; 6. Alunos respondem a questionamentos.

Para o método de Aprendizagem Baseada em Instrução apresentar resultados, satisfatórios, alguns desafios ainda precisam ser superados. Há que se salientar que grande parte desses estudantes ainda são resistentes quanto à realização de leituras prévias e não desenvolveram disciplina, concentração que levariam ao hábito de leitura. Também é possível observar a falta assumência, de postura ativa, de interesse pessoal pela produção de conhecimentos.

\section{CONSIDERAÇÕES FINAIS}

Os professores da Educação Básica, especialmente os que lecionam a partir do $6^{\circ}$ ano do Ensino Fundamental, quase todos professores possuem uma graduação. Poucos são graduandos. Contudo, boa parte desses não atuam em disciplinas da área de sua formação. Quase metade dos que atuam na docência, possuem especialização lato sensu. Nesse universo, ficou evidente que a maioria se preocupa em planejar/preparar as aulas que ministra. Quase todos se preocupam em “dinamizar” as aulas cm técnicas e dinâmicas

Educação, Psicologia e Interfaces, Volume 2, Número 3, p. 57-70, Setembro/Dezembro, 2018. 
de ensino. O curioso é que, praticamente, não conhecem as técnicas e as tomam como "receitas de bolo".

Tais docentes seguem os passos de aplicação, mas não conseguem contextualizar suas aulas e adequá-las segundo a realidade do aluno. Da mesma forma, poucos conseguem analisar os resultados e tratá-los com processo de aprendizagem ou avaliação. Diante dessa pequena amostra é possível questionar os meandros da formação de tais professores, mas também colocar em questão seu compromisso com as práticas pedagógicas de ensino. Isso porque nas salas de formação lato sensu, quando perguntados por que escolheram fazer aquele curso, a maioria responde que é para melhorar o currículo.

Com essa concepção, há quem afirme que, durante os cursos de formação continuada ou de pós, leem o que os formadores exigem e escrevem o que os mesmos gostariam de ler. Mas, na prática, "fazem o que tem que ser feito, com o que possuem e nas condições que têm”. Os Métodos Ativos de Ensino envolvem, preferencialmente, o aluno como agente do processo de ensino-aprendizagem, o professor agora é um facilitador e orientador do processo.

Nos diferentes métodos, os alunos devem estar cientes de que eles (alunos) são os principais responsáveis pelo seu rendimento na aprendizagem, que, se alguma etapa for atropelada, o resultado final ficará comprometido.

No Método de Ensino por Problemas, o aluno recebe o tema e a questão-problema, e conta com um curto espaço de tempo para o levantamento de informações. Somente após algumas etapas ocorrerá o andamento do processo de ensino aprendizagem. Nesta proposta de ensino, os alunos recebem os temas dos conteúdos que serão trabalhados e devem trabalhar em grupos para organização dos projetos de ensino e estudo dos respectivos conteúdos, cada etapa deve ser rigorosamente supervisionada pelo professor.

O método de Ensino por Projetos requer do professor um cronograma bem definido de atividades, requer mais tempo para o processo de ensino-aprendizagem. E ainda deve-se ter um controle das etapas realizadas do projeto, e o acompanhamento do envolvimento de cada aluno do processo de desenvolvimento e execução do projeto.

O Método por Instrução é aquele que não requer do professor um preparo de um novo material pedagógico, poderá ser usado os mesmos livros de ensino, mas requer uma preparação maior das aulas. O aluno fará um estudo prévio do conteúdo que será 
Metodologias Ativas de Ensino Aprendizagem: considerações sobre Problemas, Projetos e Instrução

trabalhado na aula seguinte, responde um teste antes e vai para aula já com conceitos iniciais sobre os assuntos que o professor trabalhará em sala de aula, e, assim, na aula, ele (aluno) terá uma participação efetiva com perguntas e debates dos temas abordados.

Contudo, requer de todos os sujeitos envolvidos, dos contextos e das instituições, mudança de paradigma metodológico. Para tal, exige de todos os envolvidos, persistência na disponibilização de recursos e tempo. Importante é ressaltar que a tecnologia ajuda muito no processo de ensino-aprendizagem, entretanto, ela, por si só, não é a solução.

Independentemente do método adotado, cabe ao professor dominar plenamente o mesmo, conscientizar os alunos sobre o processo de ensino e de aprendizagem no qual Estudo realizado com financiamento da Pró-Reitoria de Pesquisa da UNIRV. Parte deste texto foi objeto de apresentação oral no Encontro PIBId/Curitiba/2016. O resultado da discussão apresentada resultou em resumo expandido, publicado na revista eletrônica PRODOCÊNCIA/UNIRV.

\section{REFERÊNCIAS}

ARAÚJO, José Carlos Souza. Fundamentos da Metodologia de Ensino Ativa (1890 -

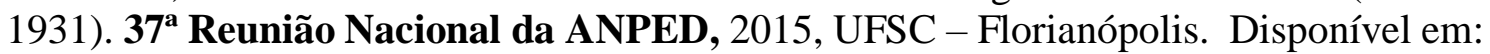
http://www.anped.org.br/sites/default/files/trabalho-gt02-4216.pdf acesso: julho de 2016.

ARAÚJO, Ulisses F. A quarta revolução educacional: a mudança de tempos, espaços e relações na escola a partir do uso de tecnologias e da inclusão social. ETD: educação temática digital, Campinas, v. 12, 2011. Número especial.

Disponível em: <http://www.fae.unicamp.br/revista/index.php/etd/article/view/2279>. Acesso em: 16 jul. 2016.

BARBOSA, E. F. e MOURA, D. G. Trabalhando com Projetos - Planejamento e Gestão de Projetos Educacionais. Petrópolis-RJ, Vozes, 2013.

CAMBI, Franco. História da Pedagogia. São Paulo: UNESP, 1999.

DECKER, I. R; BOUHUIJS, P. A. J. Aprendizagem Baseada em Problemas e Metodologia da Problematização: Identificando e analisando continuidades e descontinuidades nos processos de ensino-aprendizagem. In: ARAÚJO, U. F.; SASTRE, G. (Org.). Aprendizagem Baseada em Problemas no ensino superior. São Paulo: Summus, 2009.

DUARTE, Sérgio Guerra. Dicionário de Educação. São Paulo: Ed. Antares Nobel, 1986.

ENEMARK, S.; KAJAERDAM, F. A. Aprendizagem Baseada em Problemas na teoria e na prática: a experiência de Aalborg na inovação do projeto no ensino. In: ARAÚJO,

Educação, Psicologia e Interfaces, Volume 2, Número 3, p. 57-70, Setembro/Dezembro, 2018. 
U. F.; SASTRE, G. (Org.). Aprendizagem Baseada em Problemas no ensino superior. São Paulo: Summus, 2009.

GOLDBERG, D. E.. The Missing Basics \& Other Philosophical Reflections for the Transformation of Engineering Education. PhilSciArchive. Disponível em: http://philsci-archive.pitt.edu/4551/ (Acesso em julho de 2015).

MARIN, Maria José Sanches et al. Aspectos das fortalezas e fragilidades no uso das metodologias ativas de aprendizagem. Rev. bras. educ. med. [online]. 2010, vol.34, n.1, pp.13-20. ISSN 0100-5502. http://dx.doi.org/10.1590/S0100-55022010000100003. Acesso: julho de 2016.

MAZUR, Eric. Peer Instruction - a revolução da aprendizagem ativa. Porto Alegre: Penso, 2015.

PIMENTA, Selma Garrido. Docência no Ensino Superior. São Paulo: Cortez, 2002.

\section{Credenciais da autora}

MENDONÇA, Zilda Gonçalves de Carvalho. Doutora em Educação (UFU). Professora da Faculdade de Pedagogia, na Universidade de Rio Verde/Brasil. E-mail: zildamendonca@hotmail.com

Endereço para correspondência: Zilda Gonçalves de Carvalho Mendonça. Rua Dona Maricota, 455 - Jardim Neves. CEP: 75.901-653 - Rio Verde-Go.

Como citar este artigo (Formato ABNT): MENDONÇA, Zilda Gonçalves de Carvalho. Metodologias Ativas de Ensino Aprendizagem: considerações sobre Problemas, Projetos e Instrução. Educação, Psicologia e Interfaces, v. 2, n.3, p. 57-70, 2019.

Recebido: 07/10/2018.

Aceito: 28/10/2018. 